\title{
Impact of post-stroke impairments on activities and participation as experienced by stroke survivors in a Western Cape setting
}

\author{
Judy Cawood, B OT (US), MPhil (US) \\ Private practice
}

Surona Visagie, BSc PT (US), MSc and Phd (Health Sciences) (US)

Post-doctoral fellow, Centre for Rehabilitation Studies, University of Stellenbosch

Gubela Mji, BSc PT (MEDUNSA), HED (UNISA), MSc (UCT) and PhD (US)

Director, Centre for Rehabilitation Studies, University of Stellenbosch

\section{ABSTRACT}

Introduction: This paper explores causal connections between impairments, activity limitations and participation restrictions after stroke. Understanding the impact of impairment on activities and participation can assist with determining optimal interventions.

Methods: The study population $(N=267)$ of this descriptive study were public health care users, from the eastern sub-district of the Western Cape Metropole, who had had a stroke in 2009 or 2010. Fifty-three study participants were selected through stratified, proportional, random sampling. Data were collected using the Stroke Impact Scale-3.0 (SIS); the Modified Barthel Index (MBI); the Loewenstein Occupational Therapy Cognitive Assessment and a language screening test. Linear regressions to determine if impairments could be correlated with activity limitations and participation restrictions were done with Spearman rank correlations. T-tests were used to determine if impairments had any statistically significant impact on activities and participation.

Results: The mean SIS participation score was 31.3/100. Participation as measured by the SIS showed positive correlations with, and was impacted signifcantly by limb strength $(r=0.49 ; p<0.0 I)$, visual perception $(r=0.57 ; p<0.01)$, spatial perception $(r=0.3 I$; $p=0.02)$, motor praxis $(r=0.58 ; p<0.0 I)$, visuomotor organisation $(r=0.50 ; p<0.01)$, and thinking operations $(r=0.6 I ; p<0.0 I)$. The mean $\mathrm{MBI}$ score was 70.58/100. MBI scores showed postive correlations with, and were impacted signifcantly by limb strength $(r=0.78 ; p<0.0 I)$, hand function $(r=0.65 ; p<0.0 I)$, visual perception $(r=0.45 ; p<0.0 I)$, motor praxis $(r=0.43 ; p<0.0 I)$, visuomotor organisation $(r=0.48 ; p<0.01)$, and thinking operations $(r=0.56 ; p<0.01)$.

Conclusion: Motor, cognitive and perceptual impairments impacted activities and participation negatively. These impairments must be diagnosed and optimally managed.

Key words: Stroke, cognition, perception, activities, participation

\section{INTRODUCTION AND LITERATURE REVIEW}

The World Health Organization's (WHO) International Classification of Functioning, Disability and Health (ICF) was used as the study framework'. According to the ICF, disability is the result of a complex nonlinear interaction between health conditions that can cause impairments (loss or change of physiological or anatomical body function or structure) which might or might not curtail the ability to perform activities and participate in social roles. Participation as defined by the ICF is "involvement in life situations" I:123. Thus it encompasses the things that give meaning to peoples' lives such as employment, home making, caring for family, sports, leisure activities, spiritual involvement, management of personal affairs, and community and civic activities. Impairments, activities and participation are influenced by contextual factors which consist of environmental and personal factors'. This article focuses on the impact of impairments, typically experienced post-stroke, on activities and participation.

Stroke can result in multiple impairments of varied severity as any of the body functions controlled by the central nervous system can be affected. Paralysis, sensory, perceptual and cognitive deficits can lead to a variety of activity limitations ${ }^{2,3}$. These impairments commonly affect activities like self-care, walking, stair climbing and speech, which in turn negatively impact on home making ability, employment, leisure and sport. Post-stroke outcomes have been explored in many previous studies. South African publications have tended to focus on one of the three ICF domains such as activity limitations ${ }^{4,5}$, or a subsection of a domain, such as mobility or employment ${ }^{6,7}$, or provide information on outcomes at a point in time ${ }^{8,9}$.

Google Scholar searches where the term ICF was in turn combined with the terms activities, participation and stroke outcomes yielded three South African studies that used the ICF as a framework to explore post-stroke outcomes ${ }^{10,11,12}$. According to Rhoda $^{10}$ impairments of the upper and lower limb lead to activity limitations in self-care and mobility and restricted participation, in caring for families and employment. Mudzi and colleagues" did not explore impairments but indicated that participants struggled with completion of single and multiple tasks such as cooking meals, doing housework and interacting with other people. They also had difficulty participating in community, leisure and recreational activities. Finally Cunningham and Rhoda ${ }^{12}$ found that stairs, gravel surfaces and kerbs caused participation restrictions post stroke.

None of these studies explored causal connections between the ICF domains. Assessing and understanding the impact of impairments on activities and participation are necessary to plan optimal interventions focussed on modifying these impairments. Therefore the aim of this paper is to explore causal connections between impairments, activity limitations and participation restrictions in a group of stroke survivors. 


\section{METHODS}

A descriptive, mixed methods study was conducted. This paper focusses on the quantitative component related to participants' impairments, activity limitations and participation restrictions. All people living in a section of the eastern sub-district of the Western Cape Metropole Health District, who had a stroke between I January 2009 and 3I December 20 I0, and accessed public health services, formed the study population. This time frame was selected to ensure that participants would not be interviewed earlier than six months post-stroke. These first six months are considered the period of fastest recovery after a stroke ${ }^{13,14}$.

\section{Population and population sample}

In total 267 possible participants were identified from the records of public service hospitals, community health care centres (CHCs) and two non-governmental organisations (NGOs) - a support group for stroke survivors and another providing home based care. Excluding stoke survivors that accessed private health care might have introduced bias since this group might be systematically different from their counterparts. However, this choice was made in the context of the larger study, because service provision was also assessed. Of these, after consultation with a statistician, 53 participants were selected through stratified, proportional, random sampling to participate in the study. The number of study participants had to be low enough to ensure that detailed data collection, including physical, speech, cognitive and perceptual evaluations, could be done within a reasonable time. On the other hand numbers had to be high enough to allow statistical analysis of data $(95 \% \mathrm{Cl})$. To ensure that participants from all communities were represented, strata were formed according to geographical sub-units in the study setting. The names of stroke survivors were placed alphabetically in each stratum and then numbered. A statistician used a computergenerated programme to draw random numbers for each stratum. The number of participants from each stratum was proportional to the total number of names in the stratum.

Data was collected in $201 \mathrm{I}$ by the first author.

\section{Measurement tools}

A demographic data coding form, the Stroke Impact Scale (SIS) Version 3.0 (SIS-3) ${ }^{15}$, the Modified Barthel Index (MBI) ${ }^{16}$, the Loewenstein Occupational Therapy Cognitive Assessment (LOTCA) ${ }^{17}$ and a language screening test were used for data collection.

\section{Stroke Impact Scale, Version 3.0 (SIS-3) ${ }^{15}$}

The SIS-3 is a 58-item tool that assesses outcomes in eight domains: strength, hand function, mobility, activities of daily living, emotion, memory, communication and participation ${ }^{18}$. The participation domain includes work (voluntary and/or paid), social activities, recreational activities (quiet (e.g. reading) and active (e.g. sport)), spiritual activities, roles in family, control over own life, and helping others. Participants are asked to record their responses on a 5_point Likert scale. Item scores are summarised to determine a score between 0 and 100 for each domain. An additional question asks participants to rate their overall recovery on a scale from 0 to $I 00$.

The SIS has been shown to have excellent reliability in all domains with the exception of the emotion domain ${ }^{15,19,20}$. According to Duncan et $\mathrm{al}^{15}$ Cronbach coefficients ranged from 0.83 to 0.90 except for emotion with a coefficient of 0.57 . Carod-Artal et al ${ }^{19}$ found a range of $0.8 \mathrm{I}$ to 0.95 except for emotion at 0.48 . However, Jenkinson and collegues ${ }^{21}$ found high levels of internal consistency in all eight domains $(0.86$ to 0.95). Convergent validity was found to be adequate by Carod-Artel et $\mathrm{al}^{19}$, Jenkinson et $\mathrm{a}^{21}$ and Duncan et $\mathrm{al}^{15}$. Duncan et $\mathrm{a}^{15}$ found excellent coherence with mobility and activities of daily living measures (scores ranged from 0.82-0.84). Scores for memory and communication were lower (0.44-0.58) and the participation domain scores correlated to a moderate extent with the Short Form Health Survey (SF-36). "In conclusion, the...SIS 3.0 is a psychometrically robust specific health related quality of life measure that may be useful to evaluate the consequences of stroke in different cultural contexts" 19:2483.
The Modified Bartel Index (MBI) ${ }^{16}$

The $M B I$ assesses 10 activities of daily living (ADL) and mobility domains: personal hygiene, bathing, feeding, toilet, stair climbing, dressing, bowel control, bladder control, ambulation and wheelchair mobility and transfers. Each item is scored numerically based on the extent of assistance the person requires. A maximum numerical score of 100 can be obtained. Scores of 0-24 denote total dependency, 25-49 severe dependency, 50-74 moderate dependency and 75-90 little dependency ${ }^{22}$. Scoring was done according to the guidelines by Shah et $\mathrm{al}^{16}$. Internal consistency and validity of the $\mathrm{MBI}$ is well established as excellent ${ }^{23}$.

\section{Loewenstein Occupational Therapy Cognitive Assess- ment (LOTCA) ${ }^{17}$}

The LOTCA tests basic cognitive and perceptual skills needed for routine function in $2 \mathrm{I}$ areas of four domains i.e. orientation, visual and spatial perception, visuomotor organisation and thinking operations. The LOTCA shows excellent internal consistency with scores of $0.85,0.87$ and 0.95 for thinking operations, perception and visuomotor organisation ${ }^{10}$. Katz et al ${ }^{17}$ found through factor analysis that the LOTCA has suitable construct validly in the areas of perception, thinking operations and visuomotor organisation. According to Wang and colleagues the "LOTCA is capable of detecting cognitive impairment earlier and more comprehensively than the Mini-Mental State Examination (MMSE)" 24:367!. LOTCA scores were found to correlate positively with the MMSE scores $(r=0.934 ; p<0.00 I)^{24}$.

Severe visual impairments prevented three of the participants from completing the LOTCA

\section{Measurement of Speech and Language}

A limitation of the study was that due to time constraints it was not possible to complete a full speech and language test battery such as the Western Aphasia Battery (WAB). According to Wade ${ }^{23}$ the section of the MMSE that tests language skills is adequate for speech and language testing in certain situations. A modified version of this section of the MMSE with additional material from the WAB was used in this study. When one question is asked, as is the case in the MMSE, there can be a number of reasons why a participant could make a mistake, but if the same results are obtained with three questions, findings should be more valid. Modifications made were based on the first author's (an occupational therapist) experience over twenty years in conducting detailed evaluations of stroke survivors.

During the test participants were asked to name three common objects, perform three commands, repeat three phrases, read and carry out three instructions, and write their name, address and the numbers I to 20. Participants whose dominant hand was affected were asked to attempt the writing task with their nondominant hand and were assured that neatness did not matter. It is possible that visual impairments and or lack of education impacted on results, however, the primary author is of the opinion that material used in the LOTCA and speech and language evaluation should have been understood by most participants. Large print was used to compensate for a lack of spectacles. Participants who were blind or had never learned to read (one participant) and write (one participant) were not asked to perform the reading and writing tasks.

\section{Recording of Vision Impairments}

Participants were questioned as to whether they were experiencing any visual impairments or had previously been diagnosed with any visual impairments. Observations in terms of vision were also made by the first author while participants were completing forms or performing tests (e.g. LOTCA/Language Screening Test.) Where participants reported on or appeared to be experiencing visual problems, this was recorded on the demographic data coding form. A limitation of the study was that no formal vision screening was done. 


\section{Data collection}

The SIS-3 was translated into Afrikaans and isiXhosa which, together with English, form the dominant languages in the study setting. This involved both forward and backward translation. In the case of the other measures, questions were asked, or instructions given either by the first author or by a translator in the home language of the participant.

Data was collected at the participants' homes or a central venue depending on their choice. The primary author provided transport where needed. On average, data collection took three hours per participant. Rest periods were provided.

The data were entered onto a spreadsheet and analysed by a statistician. Linear regressions to determine if impairments could be correlated with activity limitations and participation restrictions were done with Spearman rank correlations. T-tests were used to determine if impairments had any statistically significant impact on activities and participation.

\section{Ethics}

Participation in the study was voluntary and written informed consent was obtained from each participant. Participants were assured that all personal information that could divulge their identity would be kept confidential. Each participant was assigned a number which was used on the data collection tools and spread sheets. Approval for this study was obtained from the Committee for Human Research at Stellenbosch University, and permission was obtained from the Western Cape Department of Health to access records to identify people who had strokes in 2009 and 2010.

\section{RESULTS}

\section{Demographic profile of participants}

Table I provides a summary of participants' demographic information. Their mean age was 62.56 years with the youngest participant being 29-years- old and the oldest 94.

Table I: Demographic information of participants (percentages have been rounded)

\begin{tabular}{|l|c|l|c|}
\hline Age & & Education & \\
\hline $20-30$ & $2 \%$ & No formal education & $\mathrm{II} \%$ \\
\hline $3 \mathrm{I}-40$ & $4 \%$ & Grade I-3 & $\mathrm{II} \%$ \\
\hline $4 \mathrm{I}-50$ & $6 \%$ & Grade 4-7 & $34 \%$ \\
\hline $5 \mathrm{I}-60$ & $28 \%$ & Grade 8-II & $30 \%$ \\
\hline $6 \mathrm{I}-70$ & $38 \%$ & Grade I2 & $8 \%$ \\
\hline 7I-80 & $19 \%$ & Tertiary education & $6 \%$ \\
\hline $80+$ & $4 \%$ & & \\
\hline Income of family unit & & Gender & \\
\hline No income & $6 \%$ & Male & $55 \%$ \\
\hline RI-R2000.00 & $30 \%$ & Female & $45 \%$ \\
\hline R200I.00-R5000.00 & $53 \%$ & & \\
\hline R5000.00+ & $11 \%$ & & \\
\hline
\end{tabular}

The majority of participants (86\%) had not passed grade 12 . Three of the six participants with no formal education had taught themselves to read and write. Income was mainly generated through disability grants, pensions and money from spouses and family members living on the same property.

\section{Impairments}

Sixty-two percent of the participants suffered one stroke while $38 \%$ had had two or more strokes. Having had two or more strokes might have increased the impairments assessed in this study, but since data were collected at a point in time and no comparisons on severity of impairments were made it should not have caused bias. Due to multiple strokes, some participants were affected on both sides of the body. This resulted in $60 \%$ of participants being affected on the left side and $43 \%$ on the right side of the body. Two percent of participants reported that their limbs were unaffected.

The SIS- 3 was used to evaluate impairments and Table /I provides a summary of the scores. The mean score for overall recovery was 48.3/100 and the highest mean scores were obtained in the domains of communication, memory and thinking skills. Participation and hand function had the lowest mean scores.

Table II: Summary of SIS -3 scores

\begin{tabular}{|l|c|c|c|c|c|c|}
\hline & $\begin{array}{c}\text { No } \\
\text { problem } \\
(\mathbf{1 0 0 )}\end{array}$ & $\begin{array}{c}\text { Score } \\
\text { below } \\
\mathbf{5 0}\end{array}$ & Mean & Max & Min & SD \\
\hline $\begin{array}{l}\text { Overall } \\
\text { recovery }\end{array}$ & $0 \%$ & $70 \%$ & 48.3 & 95 & 0 & 23 \\
\hline Limb strength & $2 \%$ & $70 \%$ & 44.6 & 100 & 0 & 23.8 \\
\hline Hand function & $6 \%$ & $72 \%$ & 32.9 & 100 & $\begin{array}{c}0 \\
(32 \% \\
\text { scored 0) }\end{array}$ & 32.8 \\
\hline Communication & $11 \%$ & $17 \%$ & 72.8 & 100 & 4 & 26.6 \\
\hline $\begin{array}{l}\text { Memory and } \\
\text { thinking skills }\end{array}$ & $13 \%$ & $23 \%$ & 70.8 & 100 & 18 & 25.9 \\
\hline Emotional status & $2 \%$ & $49 \%$ & 50.8 & 100 & 14 & 18.4 \\
\hline $\begin{array}{l}\text { Activities of } \\
\text { daily living }\end{array}$ & $0 \%$ & $51 \%$ & 49.1 & 98 & 0 & 29.4 \\
\hline $\begin{array}{l}\text { Home and } \\
\text { community } \\
\text { mobility }\end{array}$ & $6 \%$ & $49 \%$ & 51.5 & 100 & 0 & 28.7 \\
\hline Participation & $2 \%$ & $79 \%$ & 31.3 & 100 & 0 & 23.4 \\
\hline
\end{tabular}

Results of the speech and language test, as shown in Figure I, indicate that only a few of the participants had trouble naming objects. The biggest challenges were experienced when participants were required to repeat words, or write.

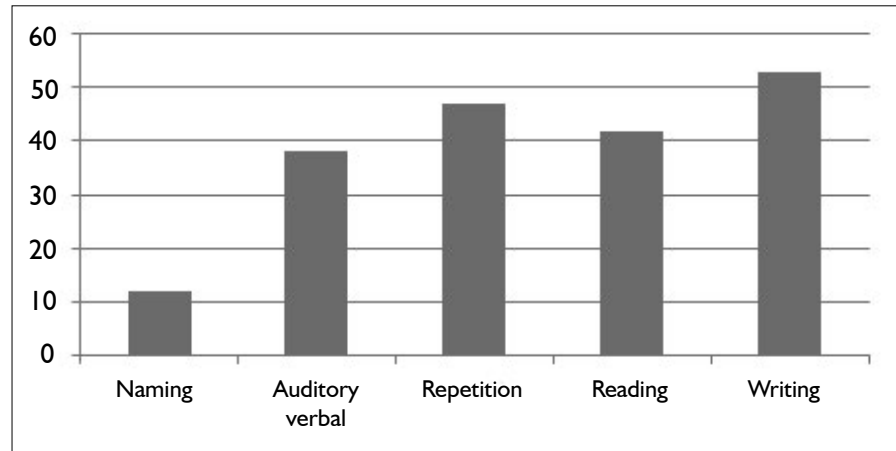

Figure I: Percentage of participants who had difficulty or could not do the tasks of the speech and language test

According to the LOTCA findings, visuomotor organisation, thinking skills, and attention and concentration were the most seriously affected cognitive and perceptual functions. For visuomotor organisation, which included planning, organising, spatial relationships, visual perception and construction, only $2 \%$ of the participants achieved the maximum score and $4 \%$ scored 27 out of a possible total of 28 . The mean score was 15.66/28. With regard to the thinking skills component, various cognitive abilities such as abstract thinking, short term memory, problem solving, reasoning, planning, organising, sequencing, simple calculations and ability to follow instructions were tested. Participants found this challenging, with only $2 \%$ obtaining the maximum score of 31 . The mean score was $|6.85 / 3|$. 
The presence of cognitive and perceptual impairments may have hindered or prevented some participants from obtaining a disability grant. A 54 year old man who experienced difficulty with planning and slowed thought processing described his inability to collate the information required to initiate the disability grant application process. A 59 year old lady with impaired memory and thinking skills had been denied a disability grant, possibly due to the assessor for the grant not being aware of the extent of her cognitive impairments.

It is possible that cognitive impairments related to dementia, the normal ageing process and other disorders caused some bias in the results. Determining whether participants had pre-existing cognitive and perceptual impairments was beyond the scope of this study.

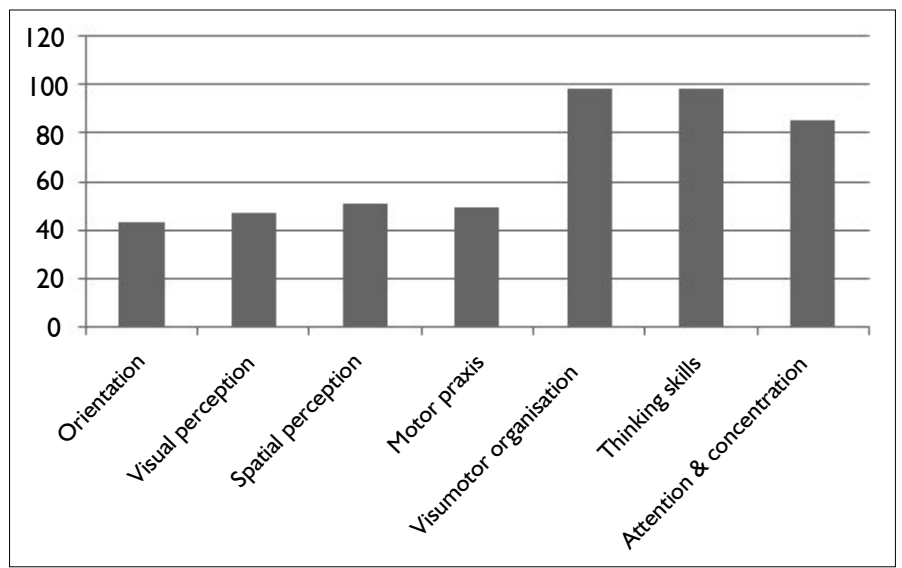

Figure 2: Percentage of participants who experienced challenges with various cognitive and perceptual aspects

Visual impairments appeared to be common and (66\%) of the participants reported increasing difficulty with their vision as they aged; $8 \%$ had hemianopia and $6 \%$ complained of double vision. A further $11 \%$ reported diabetic retinopathy, of whom two were virtually blind.

According to $\mathrm{MBI}$ scores $57 \%$ of participants were fully bowel continent, II \% were incontinent and $32 \%$ were continent some of the time but accidents occurred. Forty-five percent of participants reported being fully bladder continent, while I I \% were incontinent, the remainder, some of the time.

\section{Activity Limitations}

Activity levels were measured with the $\mathrm{MBI}$ and the mobility and ADL domains of the SIS-3. The mean MBI score was 70.58 and the median 78 out of a possible 100.

\section{Table III: Modified Barthel Index Scores}

\begin{tabular}{|l|c|c|}
\hline MBI score & $\begin{array}{c}\text { Percentage of } \\
\text { participants }\end{array}$ & Dependency level \\
\hline $0-24$ & $13 \%$ & Totally \\
\hline $25-49$ & $8 \%$ & Severely \\
\hline $50-74$ & $23 \%$ & Moderately \\
\hline $75-90$ & $21 \%$ & Mildly \\
\hline $91-100$ & $36 \%$ & Independent \\
\hline
\end{tabular}

Table III shows that $21 \%$ of the participants were totally or severely dependant and $36 \%$ were independent. Scores obtained in the various $\mathrm{MBI}$ domains are summarised in Figure 3, which shows that $59 \%$ of participants were independent in toileting and walking (to be classified as fully independent in walking the person must be able to walk $50 \mathrm{~m}$ safely indoors without assistance from another person although the use of a walking assistive device is allowed). The biggest challenges were experienced with stair climbing and propelling a wheelchair (independence requires the person to propel the wheelchair independently for $50 \mathrm{~m}$, turn corners and get to a toilet or table).
The mean SIS-3 score for activities of daily living was 49.1 and for mobility was $51.5 / 100$ as shown in Table II. The results of the SIS-3 show that only three participants considered themselves to be completely mobile at home and in the community. A comparison of SIS community mobility scores with vision problems showed that while not statistically significant $(p=0.3)$ participants with visual impairments struggled more with community mobility.

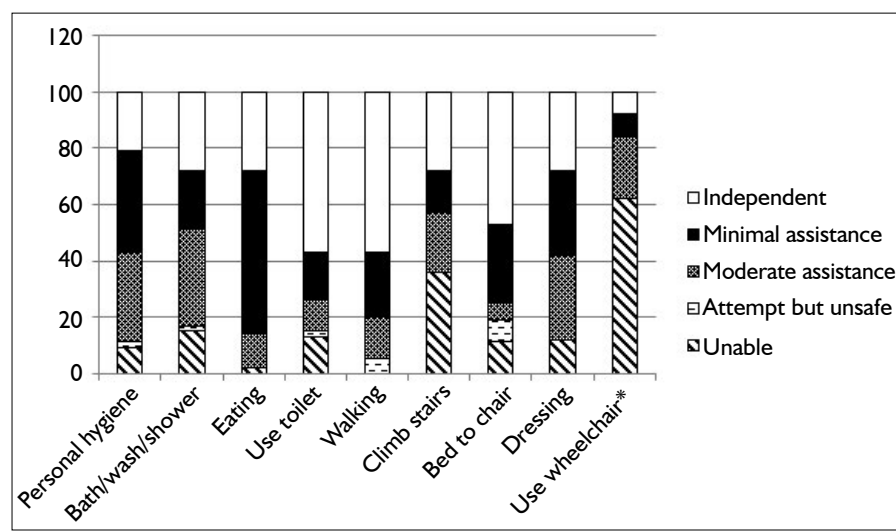

Figure 3: Scoring on various aspects of $\mathrm{MBI}$ ( $\mathrm{*}=8$ as 8 people had wheelchairs)

Table IV shows that limb strength, hand function and various cognitive and perceptual functions had a statistically significant $(p<0.0 \mathrm{I})$ impact, as measured by the $\mathrm{MBI}$, on performance of activities of daily living.

Table IV: Correlations between total MBI score and impairments

\begin{tabular}{|l|l|c|c|}
\hline Variable I & Variable 2 & $\mathbf{r}$ & $\mathbf{P}$ \\
\hline$M B I$ total & Limb strength & 0.78 & $<0.0 \mathrm{I}$ \\
\hline$M B I$ total & Hand function & 0.65 & $<0.0 \mathrm{I}$ \\
\hline$M B I$ total & Visual perception & 0.45 & $<0.0 \mathrm{I}$ \\
\hline$M B I$ total & Spatial perception & 0.25 & 0.07 \\
\hline$M B I$ total & Motor praxis & 0.43 & $<0.0 \mathrm{I}$ \\
\hline$M B I$ total & Visuomotor organisation & 0.48 & $<0.0 \mathrm{I}$ \\
\hline$M B I$ total & Thinking operations & 0.56 & $<0.0 \mathrm{I}$ \\
\hline
\end{tabular}

\section{Participation restrictions}

The majority of participants experienced restrictions in their ability to participate in social, religious, sport, leisure and employment activities as measured by the SIS-3 (Table II). Seven point five percent of the participants scored zero in this category. Table $V$ shows that cognitive and perceptual impairments as well as physical strength had a statistically significant negative impact on participation.

Table V: Impact of impairments on participation

\begin{tabular}{|l|l|c|c|}
\hline Variable I & Variable 2 & $\mathbf{r}$ & $\mathbf{p}$ \\
\hline SIS-3 Participation & Limb strength & 0.49 & $<0.0$ I \\
\hline SIS-3 Participation & Visual perception & 0.57 & $<0.01$ \\
\hline SIS-3 Participation & Spatial perception & 0.31 & 0.02 \\
\hline SIS-3 Participation & Motor praxis & 0.58 & $<0.01$ \\
\hline SIS-3Participation & $\begin{array}{l}\text { Visuomotor } \\
\text { organisation }\end{array}$ & 0.50 & $<0.01$ \\
\hline SIS-3 Participation & Thinking operations & 0.61 & $<0.01$ \\
\hline
\end{tabular}

At the time of the study, $74 \%$ of the participants were unemployed and $37 \%$ of them gave the stroke as their reason for unemployment. Nineteen percent had already retired at the time 
of the stroke. Eight percent had returned to full or part time employment (two full-time and two part-time). Although the majority of participants were over 60-years-of-age, 20 fell within the economically active group. Types of employment before the stroke included security work, building, plumbing, construction work, domestic work and gardening. Of the 16 participants who were housewives, one was able to continue in this role unaided after the stroke. Prior to the stroke, seven families conducted informal businesses or supplemented their income with odd jobs. None of them could continue with this after the stroke.

\section{DISCUSSION}

The results of this study provide a more detailed account of the possible causal connection between impairments, activity limitations and participation restrictions of stroke survivors in a South African setting. Study participants experienced activity limitations as indicated by the mean SIS-3 ADL score of 49.1 and a mean MBI score of 70.58 (Table III). Rhoda et $\mathrm{al}^{5}$, Rhoda ${ }^{10}$, and Mudzi et al ${ }^{\prime \prime}$ (MBI mean: 13) all similarly found that activities were impacted negatively by the stroke in various South African settings. Cunningham and Rhoda $^{12}$ found that activities of participants in an Eastern Cape study were less seriously affected by the stroke (MBI mean: 81.5$)$, but that mobility and self-care did cause challenges. Rhoda, Mudzi et al and Cunningham and Rhoda ${ }^{10,11,12}$ attributed activity limitations to poor physical function and decreased muscle strength, while Rhoda et $\mathrm{al}^{5}$ did not discuss possible causes. Findings from the current study showed, through statistical analysis, that muscle strength and function did indeed affect the ability to perform activities. It was further shown that perceptual and cognitive skills played a significant role in ADL. These are factors that were seemingly not formally identified in previous South African research, are in accordance with international findings ${ }^{25}$, and are recognised by many clinicians.

The mean SIS-3 participation score (3I.3) was much lower than for studies completed in Australia $(68.3)^{20}$, the United Kingdom $(59.9)^{21}$ and Brazil (50.6) ${ }^{19}$. Low levels of participation of stroke survivors in South Africa have also been described by various South African authors ${ }^{8,10,11}$. These authors pointed out challenges with mobility and environmental barriers as reasons for participation restrictions. The current study findings showed that participation was significantly negatively impacted by a combination of physical (limb strength), perceptual (visual and spatial perception, visuomotor organisation) and cognitive (thinking skills, motor praxis) impairments. International studies similarly found that cognitive and perceptual impairments had a significant negative impact on participation ${ }^{25,26,27}$. Spritzer et $\mathrm{a}^{26}$ found that even mild cognitive impairment led to significantly lower levels of participation amongst Australians who had a stroke.

Cognitive and perceptual impairments can have devastating impacts if they are not diagnosed ${ }^{2,28}$. They have a negative impact on activities and participation as shown in the results of the current study. Abstract thinking, short term memory, problem solving, reasoning, planning, following instructions and performing simple calculations are vital for budgeting, shopping and generally caring for the needs of the family unit, conducting personal affairs and participating in social activities ${ }^{29}$. If cognitive and perceptual functions are not formally assessed people may be denied financial compensation to which they are entitled. Their disability grant application might be rejected or they might have difficulty with collating information and completing the required documentation as described in the results. Not identifying cognitive and perceptual deficits can hamper return to employment in people with little physical impairment ${ }^{28,30,31}$. Taking the above facts into consideration, it is of some concern that prior to participation in the study, only one participant had been formally tested with a standardised cognitive and perceptual evaluation measure.

The evaluation and treatment of cognitive and perceptual impairments are considered to be part of the role of occupational therapists. Remediation (restoration of lost function) and adapta- tion (minimising cognitive impairments) are considered to be the traditional types of intervention provided by occupational therapists ${ }^{2}$. It has been the first author's experience that these strategies can play a role in overcoming cognitive and perceptual limitations. However, statistical proof on the effectiveness of treatment of cognitive and perceptual impairments is lacking due to the lack of research. As concluded by Hoffmann et al in a Chochrane review: "The effectiveness of occupational therapy for cognitive impairment post-stroke remains unclear"32:2.

An activity that can severely limit participation in South Africa is mobility both in the home and the community,10,11. In the current study various factors could have contributed to participants not achieving community mobility. With a mean age of 62.56 the study population can be described as elderly and pre-existing conditions such as arthritis and visual impairments may have played a role. A limitation of this study is that the number of participants who were independently mobile before the stroke was not determined. However, through the implementation of various strategies more people might have achieved community mobility. Two blind participants who had the physical ability to walk did not receive sufficient input to ensure community mobility. People who could walk indoors, but not in the community had not received wheelchairs. Those who did receive wheelchairs could often not propel the wheelchairs independently. Although perceptual impairments can impact on the ability to independently operate wheelchairs, our clinical experience is that, training in wheelchair dexterity and the issuing of the most suitable wheelchair has the potential to improve outcomes in terms of community mobility. Community mobility is also dependent on environmental facilitators such as the state of roads, kerbs and public transport. The impact of these on the mobility of study participants has been explored by Cawood and Visagie ${ }^{33}$

Continence or accident-free bladder and bowel management is another prerequisite for participation. Mamabolo et $\mathrm{al}^{4}$ found that both bladder and bowel incontinence had a significantly negative impact on functional independence of stroke survivors. The embarrassment of suffering a bowel movement or bladder voiding in public might be reason enough to stay home. Gillen ${ }^{2}$ reports urinary incontinence as a barrier to participation as considerable planning has to go into performing activities that were previously done spontaneously.

Finally $49 \%$ of participants scored below $50 \%$ for emotional status on the SIS-3. Desrosiers et $\mathrm{al}^{34}$ have indicated that emotional problems such as depression can impact participation negatively.

\section{CONCLUSION AND RECOMMENDATIONS}

This study showed that cognitive and perceptual impairments have as important an impact on activities and participation as motor function. Therefore it is essential that cognitive and perceptual impairments are diagnosed and treated, as are motor impairments. It is recommended that all stroke survivors are routinely referred for cognitive and perceptual evaluations in addition to motor and functional evaluation. In instances were cognitive and perceptual impairments are identified, the patient, family and carers should be educated about these, the problems they cause and how to manage them. The treatment of cognitive and perceptual impairments is recognised as part of the role of occupational therapists and clinically positive outcomes have been observed in this regard. However, to date the effectiveness of treatment, has not been proven through research. Thus further research on the topic is essential.

\section{ACKNOWLEDGEMENT}

The authors want to thank Professor Martin Kidd from the Centre for Statistical Consultation at Stellenbosch University for assistance with sampling and data analysis. 


\section{REFERENCES}

I. World Health Organization. International Classification of Functioning, Disability and Health. Geneva: World Health Organization, 200I.

2. Gillen G. Stroke Rehabilitation. A Function-Based Approach. Missouri: Mosby, 20II.

3. Tipping B. Issues in the long-term management of stroke. Continuing Medical Education, 2008; 26(2): 70-72.

4. Mamabolo MV, Mudzi W, Stewart AS, Mbambo NP, Olorunju S. The influence of demographic, environmental and physical factors on functional independence post-stroke. South African Journal of Physiotherapy, 2008; 64(3): 19-22.

5. Rhoda A, Mpofu R, De Weerdt W. Activity Limitations of Patients with Stroke Attending Out-patient Facilities in the Western Cape, South Africa. South African Journal of Physiotherapy, 20II; 67(2): 16-22.

6. Duff N, Ntsiea M, Muduzi W. Factors that influence return to work after stroke. Occupational Health Southern Africa, 20 I4; 20(3): 6-I 2.

7. Hassan S, Visagie S, Mji G. The achievement of community integration and productive activity outcomes by CVA survivors in the Western Cape Metro Health District. South African Journal of Occupational Therapy, 2012; 42(I): II-I6.

8. Maleka M, Stewart AS, Hale, L. The experience of living with a stroke in low urban and rural socio-economic areas of South Africa. South African Journal of Physiotherapy, 2012; 68(3): 25-29.

9. Wasserman S, De Villiers L, Bryer A. Community-based care of stroke patients in a rural African setting. South African Medical Journal, 2009; 99(8): 579-583.

10. Rhoda A. Limitations in activity and participation experienced by stroke patients: A qualitative inquiry. SA Journal of Physiotherapy, 20I 2; 68(3): 20-24.

II. Mudzi W, Stewart A, Musenge E. Community participation of patients 12 months post-stroke in Johannesburg, South Africa. African Journal of Primary Health Care Family Medicine. 2013; 5(I), Art. \#426, 9 pages.

12. Cunningham N, Rhoda, R. Outcomes of stroke patients discharged from an in-patient facility in the Eastern Cape, South Africa: A mixed methods design. South African Journal of Physiotherapy, 2014; 70(3): 26-31.

13. Kwakkel G, Kollen B, Twisk J. Impact of Time on Improvement of Outcome after Stroke. Stroke, 2006; 37(9):2348-2353.

14. De Wit L, Putman K, Schuback P, Komarek A, Angst, et al. Motor and Functional Recovery after Stroke. A Comparison of 4 European Rehabilitation Centers. Stroke, 2007; 38: 210I-2I07.

15. Duncan PW, Wallace D, Lai SM, Johnson D, Embretson S, Laster LJ. The Stroke Impact Scale Version 2.0 Evaluation of Reliability, Validity, and Sensitivity to Change. Stroke, 1999; 30: 2I3I-2I 40.

16. Shah S, Vanclay F, Cooper B. Improving the Sensitivity of the Barthel Index for Stroke Rehabilitation. Journal of Clinical Epidemiology, 1989; 42(8): 703-709.

17. Katz N, Hartman-Maeir A, Ring H, Soroker N. Relationships of cognitive performance and daily function of clients following right hemisphere stroke: Predictive and ecological validity of the LOTCA battery. Occupational Therapy Journal of Research, 2000; 20(I): 3-I7.

18. Lai S, Studenski S, Duncan PW, Perera S. Persisting Consequences of Stroke Measured by the Stroke Impact Scale. Stroke, 2002; 33: 1840-1844.

19. Carod-Artal FJ, Coral LF, Trizotto DS, Moreira CM. The Stroke Impact Scale 3.0. Evaluation of Acceptability, Reliability, and Validity of the Brazilian Version. Stroke, 2008; 39: 2477-2484.

20. Edwards B, O'Connell B. Internal consistency and validity of the Stroke Impact Scale 2.0 (SIS 2.0) and SIS- 16 in an Australian sample. Quality of Life Research, 2003; 12(8): I I 27-I I 35.

2I. Jenkinson C, Fitzpatrick R, Crocker H, Peters M. The Stroke Impact Scale Validation in a UK Setting and Development of a SIS Short Form and SIS Index. Stroke, 2013; 44: 2532-2535.

22. Australian Government Department of Health. The claim and advance Payment Cycle - Information for the Transition Care Program, Modified Barthel Index. 2006. Available: www.health.gov.au/internet/ main/publishing.nsf (Accessed 24 July 201 I).

23. Wade D. Measurement in Neurological Rehabilitation. Oxford: Oxford University Press, 1996.

24. Wang S-Y, Gong Z-K, Sen J, Han L, Zhang M, Chen W. The usefulness of the Loewenstein Occupational Therapy Cognition Assessment in evaluating cognitive function in patients with stroke. European Review for Medical and Pharmacological Sciences, 2014; 18: 3665-3672.

25. Viscogliosi C, Desrosiers J, Belleville S, Caron CD, Sak B. Differences in Participation According to Specific Cognitive Deficits Following a Stroke. Applied Neuropsychology, 201 I; 18:I I7-I 26.

26. Spitzer J, Tse, T, Baum CM, Carey LM. Mild Impairment of Cognition Impacts on Activity Participation after Stroke in a CommunityDwelling Australian Cohort. Occupation, Participation and Health, 20II; 3I(I): S8-SI5.

27. Beaudoin AJ, Fournier B, Julien-Caron L, Moleski L, Simard J, Mercier L, Desrosiers J. Visuoperceptual deficits and participation in older adults after stroke. Australian Occupational Therapy Journal, 2013; $60: 260-266$.

28. Jaillard A, Naegele B, Trabucco-Miguel S, LeBas JF, Hommel M. Hidden Dysfunctioning in Sub-acute Stroke. Stroke, 2009; (40): 2473-2479.

29. Akbaria S, Lyden PD, Kamali M, Akbarfahimi M. Correlations among impairment, daily activities and thinking operations after stroke. NeuroRehabilitation, 2013; 33(I): 153-160.

30. Hommel M, Trabucco-Miguel S, Naegele B, Gonnet N, Jaillard A. Cognitive determinants of social functioning after a first-ever mild to moderate stroke at vocational age. Journal of Neurology, Neurosurgery and Psychiatry, 2009; 80(8): 876-880.

31. Lindström B, Röding J, Sundelin G. Positive Attitudes and Preserved High Level of Motor Performance are Important Factors for Return to Work in Younger Persons After Stroke: A National Survey. Journal Rehabilitation Medicine, 2009; 4I(9): 7I4-20.

32. Hoffmann T, Bennett S, Koh CL, McKenna KT. Occupational therapy for cognitive impairment in stroke patients (Review). The Cochrane Library, 2010, 9.

33. Cawood J, Visagie S. Environmental factors influencing participation of stroke survivors in the Western Cape Province of South Africa. African Journal of Disability. 2015; 4(I), Art. \# 198,9 pages. http// dx.doi.org/10.4102/ajod.v4il. 198.

34. Desrosiers J, Noreau L, Rochette A, Bourbonnais D, Bravo G, Bourget A. Predictors of long-term participation after stroke. Disability and Rehabilitation, 2006; 28(4):221-230.

Corresponding Author

Judy Cawood

judycawood@gmail.com 